EXTENDED REPORT

\title{
Advantage of three dimensional animated teaching over traditional surgical videos for teaching ophthalmic surgery: a randomised study
}

\author{
A Prinz, M Bolz, O Findl
}

Br J Ophthalmol 2005;89:1495-1499. doi: 10.1136/bjo.2005.075077

See end of article for authors' affiliations .......................

Correspondence to: Oliver Findl, MD, Department of Ophthalmology, Medical University of Vienna, Waehringer Guertel' 1820, 1090 Wien, Austria oliver.findl@meduniwien. ac.at

Accepted for publication 1 July 2005
Background/aim: Owing to the complex topographical aspects of ophthalmic surgery, teaching with conventional surgical videos has led to a poor understanding among medical students. A novel multimedia three dimensional (3D) computer animated program, called "Ophthalmic Operation Vienna" has been developed, where surgical videos are accompanied by 3D animated sequences of all surgical steps for five operations. The aim of the study was to assess the effect of 3D animations on the understanding of cataract and glaucoma surgery among medical students.

Method: Set in the Medical University of Vienna, Department of Ophthalmology, 172 students were randomised into two groups: a 3D group $(n=90)$, that saw the 3D animations and video sequences, and a control group $(n=82)$, that saw only the surgical videos. The narrated text was identical for both groups. After the presentation, students were questioned and tested using multiple choice questions.

Results: Students in the 3D group found the interactive multimedia teaching methods to be a valuable supplement to the conventional surgical videos. The 3D group outperformed the control group not only in topographical understanding by $16 \%(p<0.0001)$, but also in theoretical understanding by $7 \%$ $(p<0.003)$. Women in the 3D group gained most by $19 \%$ over the control group $(p<0.0001)$.

Conclusions: The use of 3D animations lead to a better understanding of difficult surgical topics among medical students, especially for female users. Gender related benefits of using multimedia should be further explored.
A $\mathrm{s}$ a result of the topographically complex anatomy of the eye, ophthalmic surgery is commonly poorly understood among medical students. Conventional teaching methods, such as surgical videos, are unsuitable because of the absence of the third dimension. The use of multimedia components such as graphics, sound, videos, and animations can theoretically facilitate the learning process. ${ }^{1}$ An innovative, multimedia based way of presenting the important surgical steps may improve the visual and spatial ability of the users, whether medical students, ophthalmologists in training, or even patients planned to have eye surgery.

The idea of combining conventional surgical videos with three dimensional (3D) animations was realised in the project "Ophthalmic Operation Vienna." This was a cooperation project of the Department of Ophthalmology, Medical University of Vienna and a multimedia class of the graphical school "Höhere Graphische Bundes Lehr und Versuchsanstalt Wien XIV." The surgical procedure of the five most common operations in ophthalmology are presented on two DVDs. These are visualised as commented videos and 3D animations of surgical steps that run in parallel. A model eye was constructed for this project based on the real dimensions of the eye and a storyboard was developed based on the actual surgical videos.

The aim of this randomised study was to evaluate the effect of 3D animated sequences of surgical procedures in ophthalmology on the topographical understanding of medical students.

\section{MATERIAL AND METHODS}

A specially developed multimedia project for illustrating ophthalmic surgery, named "Ophthalmic Operation Vienna" was used in this study. It encompasses five surgical procedures: cataract, glaucoma, retinal detachment, vitrectomy, and ablative refractive surgery. For this study, only the procedures cataract and glaucoma were evaluated. Every surgical procedure is divided into multiple chapters, each containing a surgical step. Overall length of each surgical procedure is approximately 10 minutes. A video filmed through the operating microscope, the so called surgeon's view, is shown at the original speed. Additionally, the operations were filmed simultaneously with a camera from the side to give an overview of the surgical setting, the so called bystander's view. The third "view" of the project is a $3 \mathrm{D}$ animated sequence, usually shown with a sectional model eye, the so called 3D view. The 3D animations were developed with professional software (3D Studio max, Discreet, Montreal, Canada) using a specially developed model eye for this project. The most time and effort were spent on creating the 3D animations. To allow for good overview and understanding, a compromise was made concerning the detail and texture of the anatomical structures of the model eye and, additionally, the structures were also colour coded (see fig 1).

In principle, the three views can be shown separately in full screen, or together in a triple view (fig 1). Another alternative is the director's cut, which includes the 3D animation followed by the surgeon's view and some short sequences of the bystander's view. The videos and 3D animation run in parallel and allow the user to switch between them using the multiangle feature of the DVD player. This was also the reason why two double layered DVDs were necessary. The DVD is professionally narrated in English and German to explain each surgical step.

Abbreviations: $3 \mathrm{D}$, three dimensional; $M C Q$, multiple choice questions 

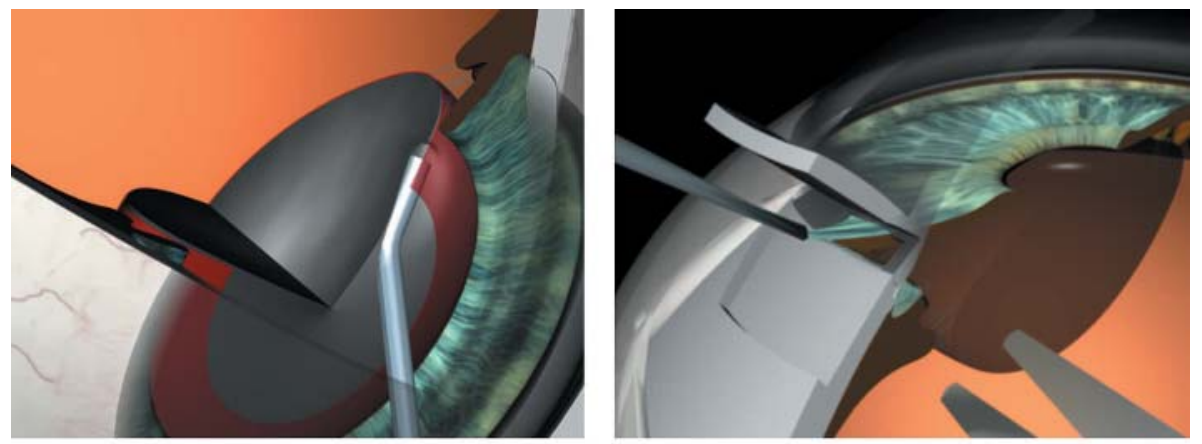

Figure 1 Screenshots of multimedia teaching project "Ophthalmic Operation Vienna": 3D animation of cataract (left, upper) and glaucoma (right, upper) surgery, bystander video view (left, lower) and triple view with all views shown simultaneously (right, lower).
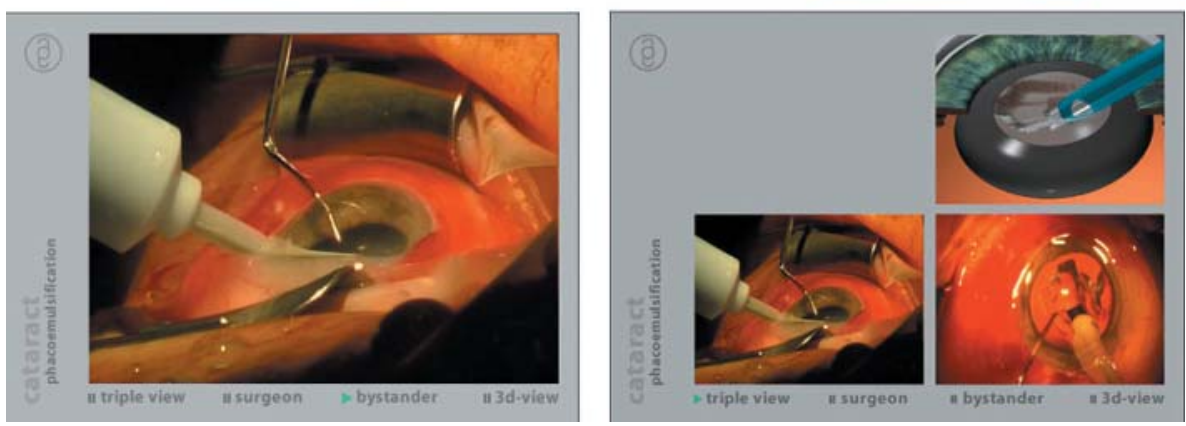

\section{Study design}

Through a period of 8 weeks, four regular practical courses in ophthalmology were held at the Medical University of Vienna. Within the course blocks of two consecutive weeks (10 working days) students were also attending lectures. Alltogether, 172 medical students were included in this study. Because of the large number of students, each course block is subdivided into two parallel classes. During the course both classes were scheduled for a video presentation of cataract and glaucoma surgery: the A class in the first week (on the fourth day of the course) and the B class in the second week (on the eighth day of the course). Therefore, a class of approximately 25 students was included in our study per week. Each student class was randomly assigned to the 3D or control groups of the study, according to a randomisation list derived from a table of random numbers. A block randomisation was applied to ensure a balance between first and second weeks of courses. The presentations were presented over a PC beamer in the same lecture theatre. Before the presentation was started, students were informed about the study and given the choice to participate by anonymously answering a questionnaire following the presentation. The control group saw the surgeon's view of the cataract and glaucoma procedures. The 3D group saw the director's cut of the same procedures, which includes the 3D animations in addition to the surgeon's view sequences identical to those in the control group. The narrated comments were identical in both groups. After the presentation of the cataract and glaucoma surgical procedures, the students evaluated the teaching project and, if applicable, the 3D animations, by using a questionnaire of five and 10 statements, respectively. A four level ordinal scale ( 1 , fully agree, 4, disagree) was used for the statements in the questionnaire.

Additionally, a multiple choice test of 19 questions that focused on the topics of cataract and glaucoma surgery was presented. It consisted of two question parts: cataract $(n=9)$ and glaucoma $(n=10)$. For the statistical analysis, multiple choice questions (MCQ) that assessed spatial knowledge with allocation of each surgical step to the anatomical tissue involved were combined in the category of topographical understanding questions $(\mathrm{n}=8)$. Questions that assessed more theoretical knowledge of the surgical procedures and why the surgical steps are performed were combined in the category of theoretical understanding questions $(n=11)$. The MCQs were aimed at specifically verifying the level of knowledge gained based on the same narrated information (shown in both groups) during the presentation. Therefore, the questionnaire was constructed considering all details in the surgical procedure from the wound construction, over exactly predefined anatomical structures, their removal with instruments and, finally, the type of wound adaptation. After completing and handing in the questionnaire, the students in the control groups received an opportunity to view the missed 3D animation sequences.

The reported relative (\%) results refer to the differences in the correct scores on the different sections of the MCQs. For instance, students in the 3D group achieved $12 \%$ better test results considering the entire questionnaire, which means 2.6 items more correctly answered in 19 MCQs than in the control group.

\section{Statistical analyses of data trends}

The data are presented as means and 95\% confidence intervals (CI). The two sided unpaired Student's $t$ test was applied to the data. Probability values of less then 0.05 were considered to be statistically significant. Reliability analysis of the multiple choice questionnaire was calculated with Cronbach's alpha coefficient that measures the internal consistency. This coefficient of test scores is obtained from a single test and is a function of the number of test items and the average intercorrelation among the items. A coefficient of 0.7 to 1 indicates a high reliability.

\section{RESULTS}

The randomisation of groups resulted in 90 students in the $3 \mathrm{D}$ group ( 55 women/35 men) and 82 in the control group (50 women/32 men).

Concerning the general questions in the questionnaire, significant differences between the two groups were found for most criteria (see table 1). 
Table 1 Evaluation by students $(n=172)$ of the presentation using a questionnaire, scale from "fully agree" $(1)$ to "disagree" (4)

\begin{tabular}{|c|c|c|c|}
\hline & $3 D$ group $(n=90)$ & Control group ( $n=82$ ) & \\
\hline Criteria & Mean (range) & Mean (range) & p Value \\
\hline $\begin{array}{l}\text { Satisfaction with the presentation } \\
\text { Useful learning aid } \\
\text { Intelligibility for cataract surgery } \\
\text { Intelligibility for glaucoma surgery } \\
\text { Improvement of spatial ability }\end{array}$ & $\begin{array}{l}1.2(1-3) \\
1.4(1-3) \\
1.7(1-3) \\
1.6(1-3) \\
1.4(1-3)\end{array}$ & $\begin{array}{l}1.3(1-4) \\
1.6(1-4) \\
1.7(1-3) \\
1.8(1-3) \\
1.7(1-4)\end{array}$ & $\begin{array}{l}0.14 \\
0.02 \\
0.69 \\
0.03 \\
0.01\end{array}$ \\
\hline
\end{tabular}

The largest difference in rating was found for the improvement of the spatial ability, with a mean better grade of 0.3 for the $3 \mathrm{D}$ group.

The 3D animation was confirmed to be an important and useful supplement to conventional surgical videos and it was suggested to use similar 3D animations in teaching of various other topics in medicine (fig 2).

The results (percentage of correct answers) of both groups on the multiple choice test, testing the topographical and the theoretical understanding of the operations, are illustrated in figure 3. The 3D group outperformed the control group not only in the topographical understanding tasks $(\mathrm{p}<0.001)$, but also in the theoretical understanding questions $(\mathrm{p}<0.001)$. An acceptable reliability of the entire multiple choice questionnaire was found with a Cronbach's alpha of 0.69.

The differences between mean results of the tests of both groups are presented in table 2. Female students in the 3D group achieved significantly better test results in all categories, than in the control (video) group. This was not the case with male students. No significant difference was found between the first and the second week within both groups.

\section{DISCUSSION}

The use of multimedia in e-learning is indispensable when one considers that a person usually retains only $10-15 \%$ of that which is read, $10-20 \%$ of what is heard, and $20-30 \%$ of what is seen, but when audio and video materials are presented side by side the retention of knowledge increases to $40-50 \% .^{2}$ In this study, we compared the results of two different approaches to teaching medical students about ophthalmic surgery. Videos supported with 3D computer

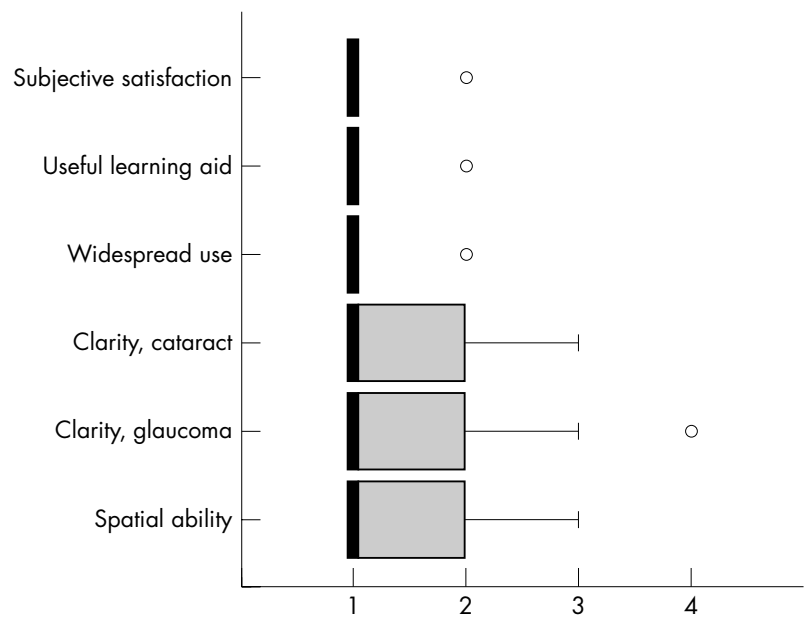

Figure 2 Evaluation of 3D animations by students of the 3D group $(n=90)$ using a questionnaire, scale from "fully agree" (1) to "disagree" (4). Boxes represent the interquartile range, bold lines the median, whiskers the non-outlier range, and circles the outliers.
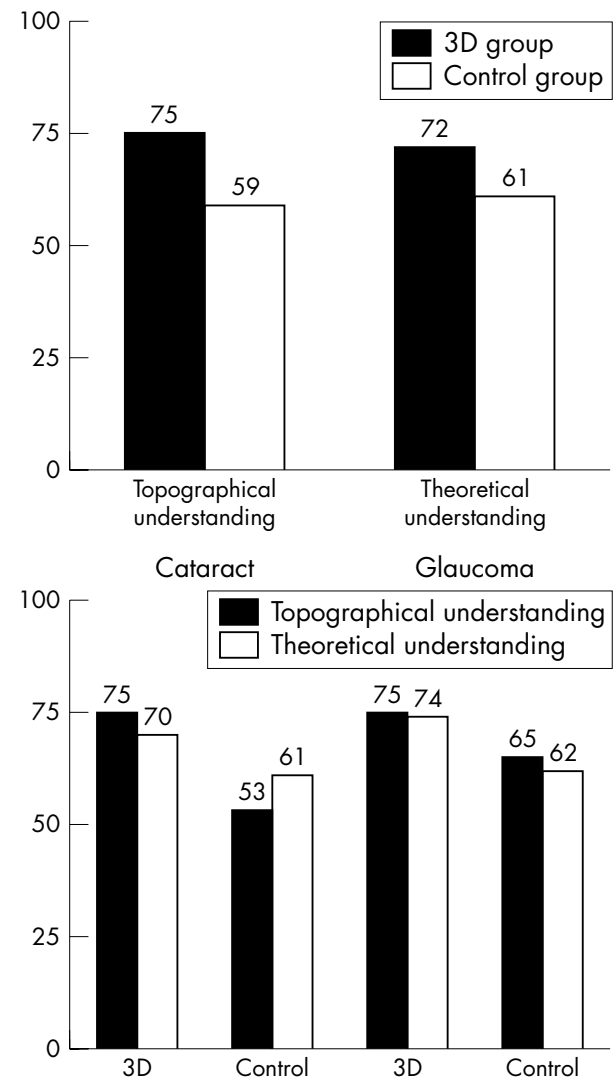

Figure 3 (Upper) Percentage of correct answers in the 3D and control groups for topographical (8 MCQ) and theoretical MCQs (11 MCQ). (Lower) Percentage of correct answers for topographical and theoretical MCQs for cataract and glaucoma in the 3D and control groups.

animations resulted in a difference of approximately one more correct answered MCQs of students as well for cataract (14\%) and for glaucoma (11\%) surgery compared to the common surgical videos alone. This result confirms those of Glittenberg et al, ${ }^{3}$ that showed the effectiveness of computer assisted 3D animation in teaching neuro-ophthalmology to medical students.

Also, our study extended the findings of several studies, ${ }^{134}$ showing a great acceptance and support of multimedia assisted education among students.

To our knowledge, "Ophthalmic Operation Vienna" is the first teaching project and learning aid for ophthalmic surgery, which systematically presents each surgical step using 3D animation and multiple view videos.

Nevertheless, there may be some limitations to our study. With respect to the study design, the internal validity needs to be questioned as both groups may not be comparable (selection bias). One of the reasons for the absence of a 
Table 2 Improvement of 3D versus control group for correctly answered multiple choice questions (MCQ) about cataract and glaucoma surgery and also separated according to gender

\begin{tabular}{|c|c|c|c|}
\hline \multirow[b]{3}{*}{ Correctly answered MCQ (\%) } & All & \multirow{3}{*}{$\begin{array}{l}\text { Female } \\
3 D n=55 \\
\text { control } n=50\end{array}$} & \multirow{3}{*}{$\begin{array}{l}\text { Male } \\
\text { 3D } n=35 \\
\text { control } n=32\end{array}$} \\
\hline & \multirow{2}{*}{$\begin{array}{l}3 D n=90 \\
\text { control } n=82\end{array}$} & & \\
\hline & & & \\
\hline $\begin{array}{l}\text { All MCQ }(n=19) \\
\text { Cl }(95 \%)\end{array}$ & $\begin{array}{l}12 \% \\
(7 \text { to } 17) \\
p<0.0001\end{array}$ & $\begin{array}{l}19 \% \\
(12 \text { to } 26) \\
p<0.0001\end{array}$ & $\begin{array}{l}8 \% \\
(-1 \text { to } 17) \\
p=0.08\end{array}$ \\
\hline $\begin{array}{l}\text { Cataract MCQ }(n=9) \\
\mathrm{Cl}(95 \%)\end{array}$ & $\begin{array}{l}14 \% \\
(7 \text { to } 21) \\
p<0.0001\end{array}$ & $\begin{array}{l}20 \% \\
(12 \text { to } 28) \\
p<0.0001\end{array}$ & $\begin{array}{l}9 \% \\
(-1 \text { to } 19) \\
p=0.16\end{array}$ \\
\hline $\begin{array}{l}\text { Glaucoma MCQ }(n=10) \\
\text { Cl }(95 \%)\end{array}$ & $\begin{array}{l}11 \% \\
(5 \text { to } 17) \\
p=0.0002\end{array}$ & $\begin{array}{l}14 \% \\
(6 \text { to } 22) \\
p=0.0005\end{array}$ & $\begin{array}{l}7 \% \\
(-1 \text { to } 15) \\
p=0.12\end{array}$ \\
\hline $\begin{array}{l}\text { Predominantly topographical understanding MCQ }(n=8) \\
\mathrm{Cl}(95 \%)\end{array}$ & $\begin{array}{l}16 \% \\
(10 \text { to } 22) \\
p<0.0001\end{array}$ & $\begin{array}{l}19 \% \\
(12 \text { to } 26) \\
p<0.0001\end{array}$ & $\begin{array}{l}10 \% \\
(-1 \text { to } 21) \\
p=0.03\end{array}$ \\
\hline $\begin{array}{l}\text { Predominantly theoretical understanding MCQ }(n=11) \\
\text { CI }(95 \%)\end{array}$ & $\begin{array}{l}7 \% \\
(1 \text { to } 13) \\
p=0.002\end{array}$ & $\begin{array}{l}14 \% \\
(7 \text { to } 21) \\
p=0.0001\end{array}$ & $\begin{array}{l}4 \% \\
(-5 \text { to } 13) \\
p=0.38\end{array}$ \\
\hline
\end{tabular}

Questions also grouped according to predominantly topographical and theoretical understanding. Mean relative difference $(\%)$ in correct answered MCQ (3D control), 95\% confidence interval (CI), $\mathrm{p}$ value of unpaired $\mathrm{t}$ test. Positive values indicate a better performance of the 3D group compared to the control group.

pretest was that we assumed a normal distribution of the students' pre-knowledge. The students were grouped coincidentally, and these groups were randomly allocated to 3D or control. With respect to the possible "diffusion of treatment" no preventive measures were used, since the only access to the tested DVD was given to the control group only after collecting the questionnaire. With a Cronbach's alpha of 0.69 , the reliability of the multiple choice measure suggests an acceptable intercorrelation of the multiple choice questionnaire. Other important aspects of evaluating novel educational programs such as social applicability, social educative relevance (one more/less correct answer), and long time effects need to be further assessed.

Another limitation of this study may be that no standardised visual spatial tests such as mental rotation were used. There are different opinions as to how important and predictive the innate visual and spatial ability may be relating to success in learning. ${ }^{5-7}$ Considering the gender differences, some studies have found that men outperform women with regard to spatial ability. ${ }^{8}$ Several variables are assumed to be responsible, such as functional hemispheric asymmetry and the possible influence of the menstrual cycle phase on that asymmetry. ${ }^{10} 11$ Based on the theoretical and empirical principles of several evolutionary models, sexual selection generally leads to the evolution of sex differences. ${ }^{12}$ The range size hypothesis predicts the sex differences in spatial abilities only in polygynous species, since males are compelled to explore a larger area to maximise their reproductive success. ${ }^{13}$ The range size, or size of the territory, and mate system of polygynous rodents resulted finally in a selective modification of neuroanatomical substrate, with an increase of the hippocampus/brain ratio. ${ }^{14}$ Silverman and Eals proposed the female foraging hypothesis, based on the assumption of paleolithic women gathering food and men hunting for it. ${ }^{15}$ Considering human behaviour, the male warfare hypothesis proposes that men travel long distances in order to win in the male-male competition, rather than to hunt for food. ${ }^{16}$ In addition, sociocultural factors seem to be involved. ${ }^{17}$ However, in this study, there was no difference between male and females in either the 3D or the control groups. The implication of a meta-analysis suggested that large sex differences are found only on measures of mental rotation and smaller sex differences are found on measures of spatial perceptions. ${ }^{18}$ Our findings suggest that, mainly, women seem to benefit by improving their topographical and theoretical knowledge, after being taught with the 3D computer animation (3.6 more correct answers on 19 MCQ). Generally, the use of 3D animations seems to optimise the level of motivation and perception, so that students with less developed spatial ability achieve greater learning efficiency. ${ }^{19}$ Thus, gender related benefits of using multimedia as a teaching method may need to be considered in future studies.

\section{CONCLUSION}

Surgical videos supported with 3D computer animations resulted in an increase of spatial and theoretical understanding of ophthalmic surgery. ${ }^{20}$ Compared to the control group, there was a significant improvement of knowledge and a better acceptance of multimedia assisted teaching among students. Furthermore, women showed more benefit in being taught with a multimedia 3D animated program than men.

\section{Authors' affiliations \\ A Prinz, M Bolz, O Findl, Department of Ophthalmology, Medical University of Vienna, Vienna, Austria}

The authors have no proprietary interest in any of the materials or methods mentioned in this study

\section{REFERENCES}

1 Mehrabi A, Gluckstein C, Benner A, et al. A new way for surgical educationdevelopment and evaluation of a computer-based training module. Computers in Biology and Medicine 2000;30:97-109.

2 Giezendanner FD. Nouvelles technologies E'ducatives multimedia au service de nouvelles strategies pedagogiques. Schweizerische medizinische Wochenschrift 1990;120:1843-57.

3 Glittenberg CG, Binder S. Computer-assisted 3D design software for teaching neuro-ophthalmology of the oculomotor system and training new retinal surgery techniques. Proc SPIE 2004;5314:275-85.

4 Sandroni C, Bocci M, Damiani F, et al. O-2 Multimedia teaching of BLS in medical students. Resuscitation 1996;31:S2.

5 Garg AX, Norman G, Sperotable L. How medical students learn spatial anatomy. Lancet 2001;357:363-4.

6 Wanzel KR, Hamstra SJ, Anastakis DJ, et al. Effect of visual-spatial ability on learning of spatially-complex surgical skills. Lancet 2002;359:230-1.

7 Sidhu RS, Tompa D, Jang R, et al. Interpretation of three-dimensional structure from two-dimensional endovascular images: implications for educators in vascular surgery. J Vasc Surg 2004;39:1305-11.

8 Epting LK, Overman WH. Sex-sensitive tasks in men and women: a search for performance fluctuations across the menstrual cycle. Behavioral Neuroscience 1998;112:1304-17. 
9 Phillips K, Silverman I. Differences in the relationship of menstrual cycle phase to spatial performance on two- and three-dimensional tasks. Hormones and Behaviour 1997;32:167-75.

10 Roberts JE, Bell MA. Two- and three-dimensional mental rotation tasks lead to different parietal laterality for men and women. Int J Psychophysiol 2003;50:235-46.

11 Bibawi D, Cherry B, Hellige J. Fluctuations of perceptual asymmetry across time in women and men: effects related to the menstrual cycle. Neuropsycologia 1995;33:131-8.

12 Jones CM, Braithwaite VA, Healy SD. The evolution of sex differences in spatial ability. Behav Neurosci 2003;117:403-11.

13 Ecuyer-Dab I, Robert M. Have sex differences in spatial ability evolved from male competition for mating and female concern for survival? Cognition 2004:91:221-57.

14 Jacobs LF, Gaulin SJC, Sherry DF, et al. Evolution of spatial congnition: sexspecific patterns of spatial behavior predict hippocampal size. Proc Natl Acad Sci USA 1990;87:6349-52.
15 Eals $\mathbf{M}$, Silverman I. The hunter-gather theory of spatial sex differences: proximate factors mediating the female advantage in recall of object arrays. Ethnology and Sociobiology 1994;15:95-105.

16 Geary DC. Sexual selection and sex differences in spatial cognition. Learning and Individual Differences 1995;7:289-301.

17 McCormick CM, Teillon SM. Menstrual cycle variation in spatial ability: relation to salivary cortisol levels. Hormones and Behavior 2001;39:29-38.

18 Linn MC, Petersen AC. Emergence and characterization of sex differences in spatial ability: a meta-analysis. Child Dev 1985:56:1479-98.

19 Huk T, Steinke M, Floto C. The influece of visual spatial ability on the attitude of users towards high-quality 3D-animations in hypermedia learning environments. Word Conference on E-Learning in Corp, Govt, Health, and Higher Ed 2003:1038-41.

20 Mayer RE. The promise of multimedia learning: using the same instructional design methods across different media. Learning and Instruction 2003; 13:125-39 